\title{
Prevalence of antibiotic resistance in multi-drug resistant coagulase-negative staphylococci isolated from invasive infection in very low birth weight neonates in two Polish NICUs
}

Monika Brzychczy-Wloch", Maria Borszewska-Kornacka², Ewa Gulczynska³, Jadwiga Wojkowska-Mach', Malgorzata Sulik', Monika Grzebyk ${ }^{1}$, Malgorzata Luchter ${ }^{1}$, Piotr B Heczko ${ }^{1}$ and Malgorzata Bulanda ${ }^{5}$

\begin{abstract}
Background: Multi-drug resistant coagulaso-negative staphylococci (CNS) have become an increasing problem in nosocomial infections connected with the presence of medical devices. The paper aimed to analyze the prevalence of antibiotic resistance in CNS isolated from invasive infection in very low birth weight (VLBW) neonates.

Methods: Continuous prospective target surveillance of infections was conducted in 2009 at two Polish NICUs that participated in the Polish Neonatology Surveillance Network (PNSN). The study covered 386 neonates with VLBW ( $\leq 1500 \mathrm{~g}$ ), among which 262 cases of invasive infection were detected with predominance of CNS (123; 47\%). Altogether, 100 CNS strains were analyzed. The resistance phenotypes were determined according to EUCAST.

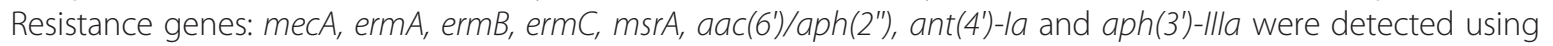
multiplex PCR.

Results: The most common species was S. epidermidis (63\%), then S. haemolyticus (28\%) and other CNS (9\%). Among S. epidermidis, $98 \%$ of isolates were resistant to methicillin, $90 \%$ to erythromycin, 39\% to clindamycin, $95 \%$ to gentamicin, $60 \%$ to amikacin, $36 \%$ to ofloxacin, $2 \%$ to tigecycline, $3 \%$ to linezolid and $13 \%$ to teicoplanin. Among S. haemolyticus isolates, 100\% were resistant to methicillin, erythromycin and gentamicin, 18\% to clindamycin, 50\% to amikacin, $86 \%$ to ofloxacin, $14 \%$ to tigecycline and $4 \%$ to teicoplanin. No resistance to linezolid was detected for S. haemolyticus isolates. Moreover, all isolates of S. epidermidis and S. haemolyticus were susceptible to vancomycin. The mecA gene was detected in $98 \%$ of S. epidermidis isolates and all of S. haemolyticus ones. Among macrolide resistance isolates, the ermC was most common in S. epidermidis (60\%) while msrA was prevalent in S. haemolyticus (93\%). The ermC gene was indicated in all isolates with $\mathrm{CMLS}_{B}$, whereas mrsA was found in isolates with $\mathrm{MS}_{B}$ phenotype. Of the aminoglycoside resistance genes, $\operatorname{aac}\left(6^{\prime}\right) / a p h\left(2^{\prime \prime}\right)$ were present alone in $83 \%$ of S. epidermidis, whereas aac (6')/aph( $\left.2^{\prime \prime}\right)$ with aph(3')-IIla were predominant in $84 \%$ of S. haemolyticus.
\end{abstract}

Conclusions: Knowing the epidemiology and antibiotic resistance of CNS isolated from invasive infection in VLBW neonates is a key step in developing targeted prevention strategies and reducing antibiotic consumption.

Keywords: Multi-drug resistant coagulase-negative staphylococci, Resistance genes, Very-low-birth-weight neonates, Nosocomial infections

\footnotetext{
*Correspondence: mbrzych@cm-uj.krakow.pl

'Department of Bacteriology, Microbial Ecology and Parasitology, Chair of

Microbiology, Jagiellonian University Medical College, Czysta Street 18,

31-121, Krakow, Poland

Full list of author information is available at the end of the article
} 


\section{Introduction}

Coagulase-negative staphylococci (CNS) rank among opportunistic pathogens being a frequent etiologic agent of nosocomial infections connected with the presence of medical devices. The cause for this should be sought in the ability of CNS to create biofilm whereby they pose a particular threat for people with valve prostheses and the ones with implants or catheters [1]. A group which is particularly susceptible to hospital infections are very low birth weight (VLBW) neonates in which CNS are identified as 48 up to $80 \%$ of all etiologic agents causing late-onset diseases (LOD). The most frequently isolated species are Staphylococcus epidermidis $(58 \%-76 \%)$ and then Staphylococcus haemolyticus (14\% - 32\%) [2-4].

Medicating infections in neonates poses a big problem as there is the need to use a therapy quickly. In the event of infections caused by hospital pathogens, the empirical treatment is adjusted based on information on drugresistance of the bacteria persisting in the ward. A high percentage of S. epidermidis and S. haemolyticus isolates coming from neonates are resistant to many antibiotics: methicillin $(86 \%-100 \%)$, gentamicin $(80 \%-100 \%)$, erythromycin $(65 \%-100 \%)$, oxacillin $(92 \%-100 \%)$, or clindamycin $(80 \%-100 \%)$ [5-7].

The growing importance of coagulase-negative staphylococci, including multidrug-resistant strains, among other etiologic agents of nosocomial infections, forcing researchers to look for the most effective ways to combat these pathogens. Therefore, the aim of the project was to analyze the prevalence of antibiotic resistance in invasive coagulase-negative staphylococci isolates derived from very low birth weight neonates hospitalized in two Polish Neonatal Intensive Care Units (NICUs).

\section{Methods}

Continuous prospective target surveillance of infections was conducted from 1.01.2009 to 31.12.2009 at two Polish NICUs that participated in the Polish Neonatology Surveillance Network (PNSN). The surveillance concerned infants hospitalized at cooperating units whose birth weight was $\leq 1500$ grams (from birth to discharge, or until the weight of 1800 grams or death). All cases of infections were subject to registration, regardless of the time of occurrence of the first symptoms as early-onset infection (EOI) or late-onset infection (LOI). Case patients were defined according to Gastmeier et al. [8] with modifications as neonates with very low birth weight (VLBW) when they had clinical signs of septicemia or of pneumonia, as previously described [9]. The study covered 386 VLBW neonates, among which 262 cases of LOI infection were detected with predominance of CNS $(123 ; 47 \%)$ including blood stream infections (54 cases, $43.9 \%$ ), pneumonia (58 cases, $47.2 \%$ ) and others.
(11 cases, 8.9\%). Altogether, one hundred invasive coagulase-negative staphylococci isolates were collected and stored at the temperature of $-80^{\circ} \mathrm{C}$. Preliminary identification of species was performed using API Staph (bioMerieux) and than multiplex PCR method according to Pereira et al. [10].

\section{Antibiotic susceptibility testing}

To determine the drug-resistance phenotype, the KirbyBauer disk diffusion method was used in which MüllerHinton 2 LAB-AGAR ${ }^{\mathrm{m}}$ (Biocorp) and antibiotic disks (Oxoid) were utilized: cefoxitin $30 \mu \mathrm{g}$, clindamycin $2 \mu \mathrm{g}$, erythromycin $15 \mu \mathrm{g}$, tigecycline $15 \mu \mathrm{g}$, ofloxacin $5 \mu \mathrm{g}$, gentamicin $10 \mu \mathrm{g}$, amikacin $30 \mu \mathrm{g}$, linezolid $10 \mu \mathrm{g}$ and the E-test method enabling determination of MIC (Minimal Inhibitory Concentration) for teicoplanin and vancomycin (bioMerieux). The results were interpreted according to EUCAST (The European Committee on Antimicrobial Susceptibility Testing) 2012 [10].

\section{Polymerase chain reaction, PCR}

To isolate DNA, the Genomic Mini Set (A\&A Biotechnology) was used according to the manufacturer's protocol. The presence of species-specific genes to $S$. haemolyticus or S. epidermidis and methicillin-resistance mecA gene was confirmed using multiplex PCR amplification according to Pereira et al. [11] with specific primers (Genomed). To detect genes coding the erythromycin-resistance, the multiplex PCR reaction was conducted on ermA, erm $C, m s r A$ genes and PCR on the ermB gene, according to the procedure described by Zmantar et al. [12]. The determination of $\operatorname{aac}\left(6^{\prime}\right) / \operatorname{aph}\left(2^{\prime \prime}\right)$, aph(3')-IIIa and ant (4')-Ia genes coding the aminoglycoside-resistance was conducted according to the procedure by Choi et al. [13]. The final pictures from electrophoresis were processed using QuantityOne software, as well as GelDoc2000 device (Bio-Rad, USA).

\section{Results}

The species identification with the multiplex PCR indicated that $63 \%$ of the tested CNS isolates belonged to S. epidermidis species, while $28 \%$ to $S$. haemolyticus (Figure 1). The remaining 9\% $(n=9)$ of isolates belonged to other CNS species, including $4 \%(\mathrm{n}=4)$ S. warneri, $2 \%(\mathrm{n}=2)$ S. hominis, $2 \%(\mathrm{n}=2)$ S. xylosus and $1 \%(\mathrm{n}=1)$ S. capitis.

A detailed analysis of drug resistance with the use of phenotypic and genotypic methods was carried out for isolates of the species S. epidermidis $(\mathrm{n}=63)$ and $S$. haemolyticus $(\mathrm{n}=28)$. Among the isolates tested, there was a very high percentage of multi-drug resistant strains. Among S. epidermidis, 98\% $(\mathrm{n}=62)$ of isolates were resistant to methicillin, $90 \%(\mathrm{n}=57)$ to erythromycin, $39 \%(\mathrm{n}=25)$ to clindamycin, $95 \%(\mathrm{n}=60)$ to gentamicin, 


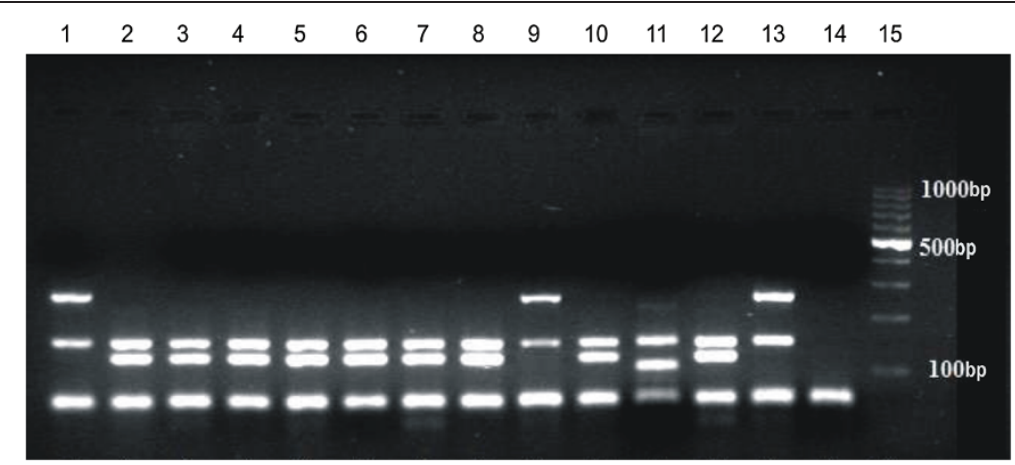

Figure 1 An example of the outcome of the multiplex PCR reaction for determining the species of Staphylococcus aureus (108 bp), Staphylococcus epidermidis (124 bp), Staphylococcus haemolyticus (271 bp) and for detecting the presence of mecA gene (154 bp). Legend: Lanes 1 - 10 studied samples; 11 - positive control reference S. aureus ATCC 33592; 2 - positive control reference S. epidermidis ATCC 700296; 13 - positive control reference S. haemolyticus ATCC 29970, 14 - negative control; 15 - marker (Eurx Perfect TM 100 bp DNA Ladder).

$60 \%(\mathrm{n}=38)$ to amikacin, $36 \%(\mathrm{n}=23)$ to ofloxacin, $2 \%$ $(\mathrm{n}=1)$ to tigecycline, $3 \%(\mathrm{n}=2)$ to linezolid and $13 \%(\mathrm{n}=8)$ to teicoplanin. Among S. haemolyticus isolates, 100\% $(\mathrm{n}=28)$ were resistant to methicillin, erythromycin and gentamicin, $18 \%(n=5)$ to clindamycin, $50 \%(n=14)$ to amikacin, $86 \%(n=24)$ to ofloxacin, $14 \%(n=4)$ to tigecycline and $4 \%(n=1)$ to teicoplanin. No resistance to linezolid was detected for S. haemolyticus isolates. Moreover, all isolates of S. epidermidis and S. haemolyticus were susceptible to vancomycin (Figure 2).

Using E-test, the values for $\mathrm{MIC}_{50}$ and $\mathrm{MIC}_{90}$ were determined for teicoplanin and vancomycin. For S. epidermidis, $\mathrm{MIC}_{50}$ and $\mathrm{MIC}_{90}$ for teicoplanin was equal to 2 and 6, respectively, while for vancomycin, it was 2 and 3. For S. haemolyticus, $\mathrm{MIC}_{50}$ and $\mathrm{MIC}_{90}$ for teicoplanin was equal to 2 and 3, respectively, and for vancomycin, it was 2 and 3.

Among S. epidermidis isolates resistant to macrolides $(\mathrm{n}=57)$, the $\mathrm{CMLS}_{\mathrm{B}}$ and $\mathrm{MS}_{\mathrm{B}}$ phenotypes were most common, and performed in $43 \%(n=25)$ and $40 \%(n=23)$ of isolates, respectively. While the $\mathrm{iMLS}_{\mathrm{B}}$ phenotype was present in $16 \%(\mathrm{n}=9)$ of $S$. epidermidis. The $\mathrm{MS}_{\mathrm{B}}$ phenotype was predominant among $S$. haemolyticus isolates $(n=28)$, and appeared in $82 \%$ of isolates $(n=23)$, whereas $\mathrm{cMLS}_{\mathrm{B}}$ phenotype was detected in $18 \%$ of the isolates $(n=5)$. In the case of $S$. heamolyticus, the $\mathrm{MS}_{\mathrm{B}}$ phenotype was not detected (Figure 3 ).

The presence of $m e c A$ gene was confirmed with the multiplex PCR method in 62 S. epidermidis (98\%) isolates and in 28 isolates of the species S. haemolyticus (100\%) (Figure 1).

The ermC gene was predominant in S. epidermidis isolates ( $\mathrm{n}=34 ; 60 \%$ ), while in $S$. haemolyticus was present only in 2 isolates (7\%). On the other hand, $m s r A$ gene was prevalent in S. haemolyticus isolates $(\mathrm{n}=26 ; 93 \%)$, while in S. epidermidis it was much less frequent $(n=23 ; 40 \%)$. It is noteworthy to remark that one of the S. haemolyticus isolates possessed both $m s r A$ and ermC genes simultaneously. The presence of ermA oraz ermB genes was not demonstrated in the studied isolate pool (Figure 4).

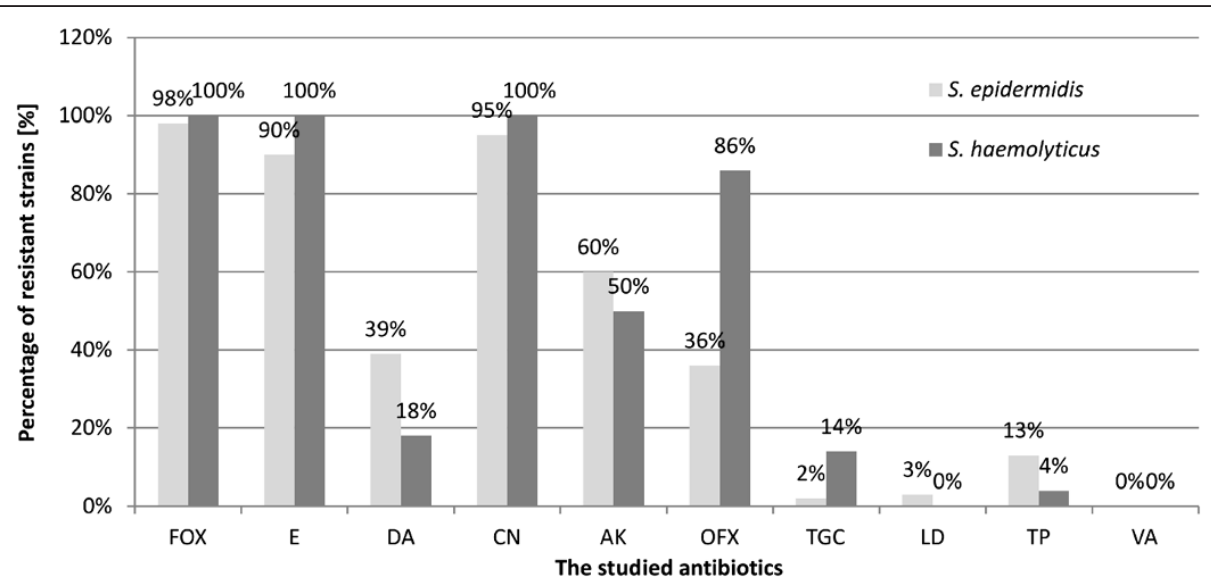

Figure 2 The percentage of isolates of the species S. epidermidis and S. haemolyticus, resistant to the studied antibiotics. 


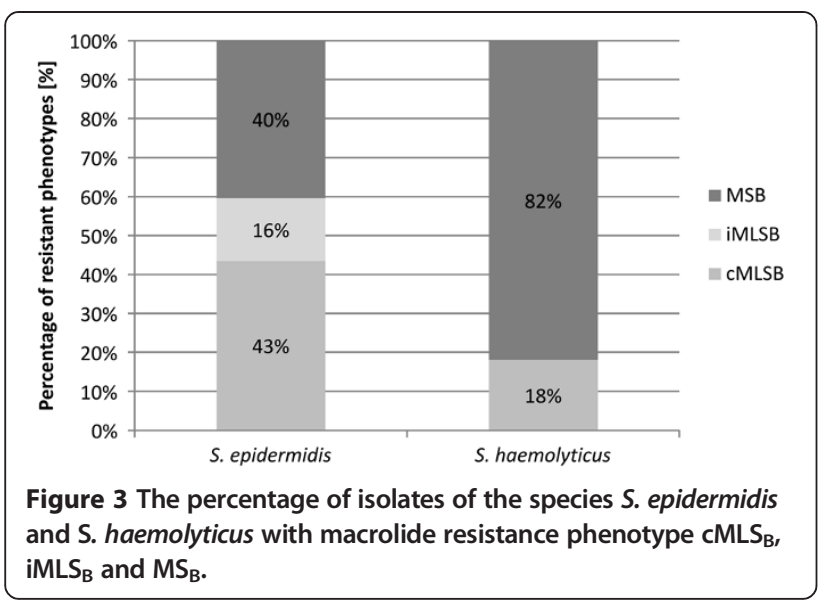

S. epidermidis isolates resistant to macrolides, of $\mathrm{CMLS}_{\mathrm{B}}$ and $\mathrm{iMLS}_{\mathrm{B}}$ resistance phenotype, possessed erm $C$ gene ( $\mathrm{n}=34 ; 60 \%$ ). While five $S$. haemolyticus isolates of cMLSB resistance phenotype demonstarted the presence of various genes, including three with $m s r A$ gene, in the second one erm $C$ and in the remaining one of ermC and msrA genes at the same time. In all $S$. epidermidis isolates $(n=23$; $100 \%)$ and S. haemoltyticus $(\mathrm{n}=23 ; 100 \%)$ of $\mathrm{MS}_{\mathrm{B}}$ phenotype, gene $m s r A$ was present.

Among the genes coding aminoglycoside resistance, $\operatorname{aac}\left(6^{\prime}\right) / \operatorname{aph}\left(2^{\prime \prime}\right)$ gene was the most frequent, and the genes more rare were $a p h\left(3^{\prime}\right)-I a$ and $a p h\left(3^{\prime}\right)$-IIIa. In $S$. epidermidis, isolates with the $\operatorname{aac}\left(6^{\prime}\right) / a p h\left(2^{\prime \prime}\right)$ gene were prevalent $(\mathrm{n}=49 ; 83 \%)$, while in $S$. haemolyticus, the aac $\left(6^{\prime}\right) / \operatorname{aph}\left(2^{\prime \prime}\right)$ was the most frequent together with aph (3')-IIIa ( $\mathrm{n}=22 ; 84 \%)$ (Figures 5 and 6).

\section{Discussion}

Infections caused by coagulase-negative staphylococci are among the most common causes of death among infants with very low birth weight [14]. This is due to the fact that staphylococcal biofilm can be formed on biomaterials, from which are made various types of devices used in patients chronically hospitalized. Bacteria growing in biofilm are characterized by an increased resistance to the host immune system and antibiotic use, making it more difficult and significantly extending the patient's hospitalization $[1,15]$.

The researched CNS isolates demonstrated multi-drug resistance. The studied S. epidermidis isolates and $S$. haemolyticus were resistant to methicillin, in $98 \%$ and $100 \%$, respectively, as well as to the majority of the remaining antibiotics that were studied. These results are concurrent with the literature data where for CNS isolated from neonatal infections the percentage of methicillin-resistant strains (methicillin-resistant coagulasenegative staphylococci, MRCNS) was in the range of $86-100 \%$, and, moreover, these bacteria was connected with multiple resistance to other antibiotics $[6,7]$.

Investigation of the mecA gene in CNS using the PCR technique is nowadays regarded as the gold standard with a view to determining methicillin resistance [11]. In our study, meticillin-resistance phenotype for all the researched strains was confirmed by the detection of the mecA gene. Similar results were described by other authors [11].

The group of isolates was characterized by high erythromycin resistance which was $84 \%$ for isolates of S. epidermidis and 100\% for S. haemolyticus. The results obtained are similar to those of Bialkowska-Hobrzanska et al. where $100 \%$ of isolates S. epidermidis and $92 \%$ of S. haemolyticus isolated from neonates were erythromycin-resistant [16], as well as similar to the data obtained by Abd El Hafez et al. where the erythromycin resistance for isolates of S. epidermidis coming from neonates was $86 \%$ [6].

Clindamycin resistance was demonstrated in $26 \%$ of isolates of S. epidermidis and $28 \%$ of isolates of S. haemolyticus. The determined percentage of clindamycin resistance was significantly lower than that described by Bialkowska-Hobrzanska et al. where for S. epidermidis it was equal to $92 \%$, and for S. haemolyticus $85 \%$ [16]; similarly, Abd El Hafez et al. demonstated $75.9 \%$ of isolates of S. epidermidis as resistant [6], and higher than

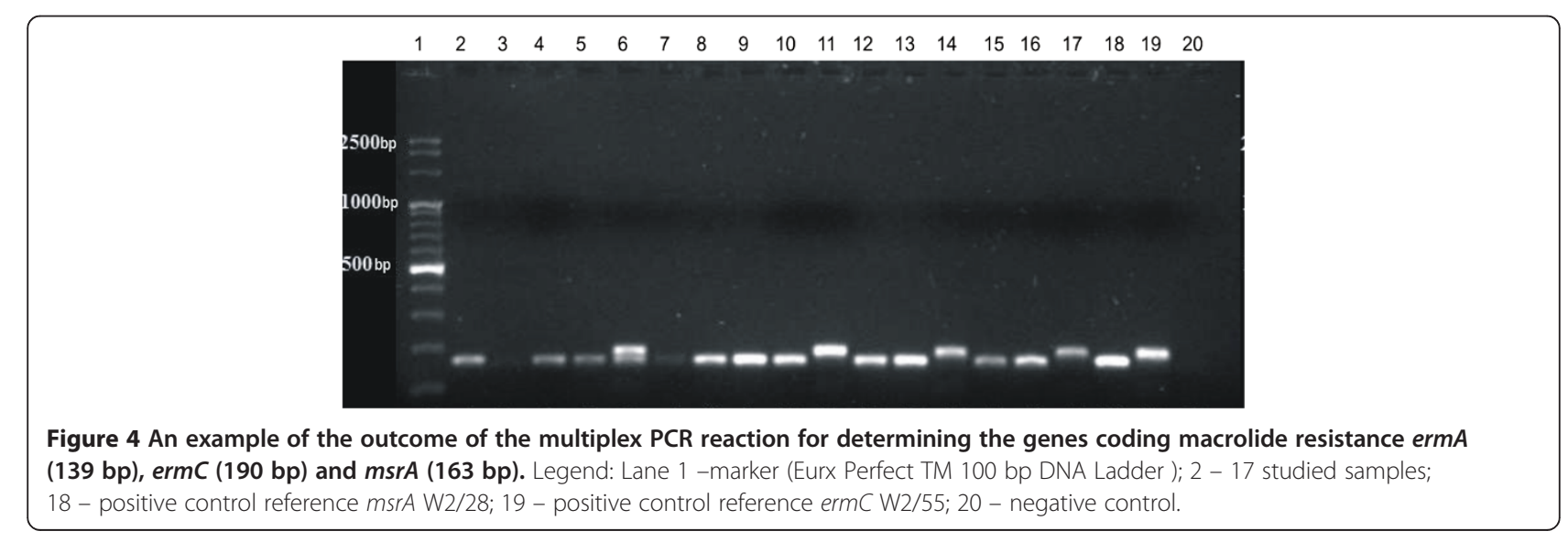




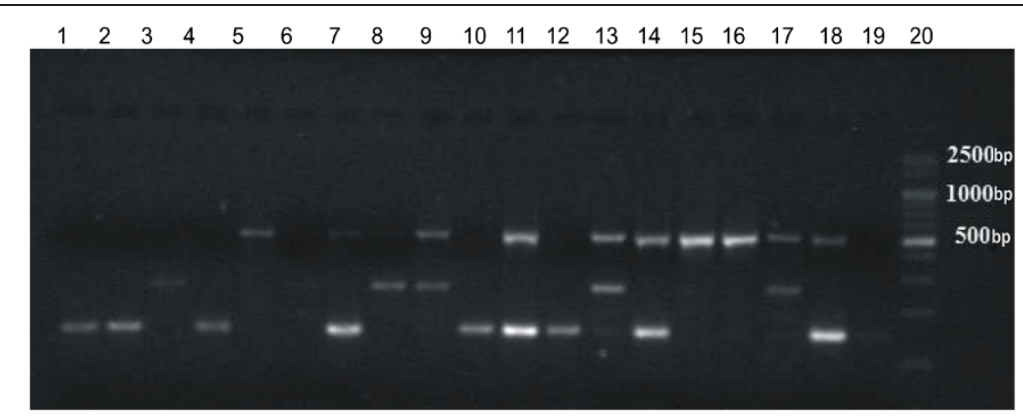

Figure 5 An example of the outcome of the multiplex PCR reaction for determining the genes coding aminoglycoside resistance aac

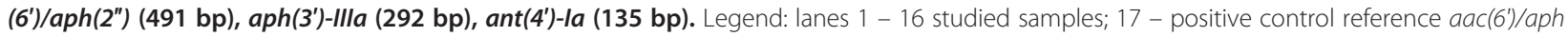

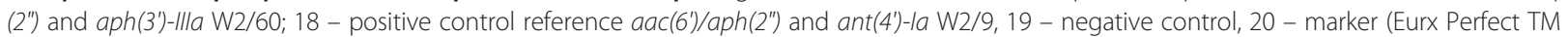
100 bp DNA Ladder).

that proven by van den Hoogen et al. equal to $15 \%$ for CNS altogether [17].

Among the S. epidermidis strains that were macrolideresistant, the $\mathrm{CMLS}_{\mathrm{B}}$ phenotype constituted $43 \%$ and $\mathrm{MS}_{\mathrm{B}} 40 \%$ whereas in S. haemolyticus the most frequently detected $\mathrm{MS}_{\mathrm{B}}$ phenotype occurred in $82 \%$ of isolates. Similar results were described by Gheradi et al. who researched CNS coming from hospital infections where $38 \%$ of isolates of S. epidermidis and $80 \%$ of isolates of S. haemolyticus had the $\mathrm{MS}_{\mathrm{B}}$ phenotype and $28.5 \%$ of isolates of S. epidermidis had the $\mathrm{CMLS}_{\mathrm{B}}$ phenotype [18]. However, Gatermann et al. clearly described a lower percentage of isolates of $S$. haemolyticus with the phenotype $\mathrm{MS}_{\mathrm{B}}$ equal to $30.2 \%$ [19]. For the isolates of S. epidermidis researched on with the $\mathrm{CMLS}_{\mathrm{B}}$ and $\mathrm{iMLS}_{\mathrm{B}}$ phenotypes, the occurrence of the erm $C$ gene was demonstrated and with the $\mathrm{MS}_{\mathrm{B}}$ phenotype, the $m s r A$ gene. However, 3 out of $5 \mathrm{~S}$. haemolyticus isolates with the $\mathrm{CMLS}_{\mathrm{B}}$ phenotype had the $m s r A$ gene, but did not have the $\operatorname{emrC}$ gene. Moreover, in the group of isolates of $S$. haemolyticus with the $\mathrm{MS}_{\mathrm{B}}$ resistance phenotype, it was demonstrated that one isolate had no msrA gene. Probably, those isolates had other genes coding the erythromycin resistance. The recorded lack of ermA and ermB genes among the isolates researched on is in conformity with the results of other scientists researching CNS who indicated the presence of these genes only as high as $1.8 \%-7.2 \%$ for erm $A$ and below $1 \%$ for ermB [20].

The gentamicin resistance was $93 \%$ for S. epidermidis, $100 \%$ for S. haemolyticus and it was higher than quoted in the literature for S. epidermidis 69.2 - 89.5\% [17,21] and for CNS altogether 85\% except the results obtained by Bialkowska-Hobrzanska et al. where for both S. epidermidis and S. haemolyticus the resistance equaled 100\% [16]. In the case of amikacin, the resistant strains of S. epidermidis constituted $51 \%$ of those studied, whereas $31 \%$ of S. haemolyticus isolates were amikacin-resistant.

From among the genes coding aminoglycoside resistance, the most frequently identified gene was $a a c\left(6^{\prime}\right) / a p h$ (2") which both in S. epidermidis and S. haemolyticus

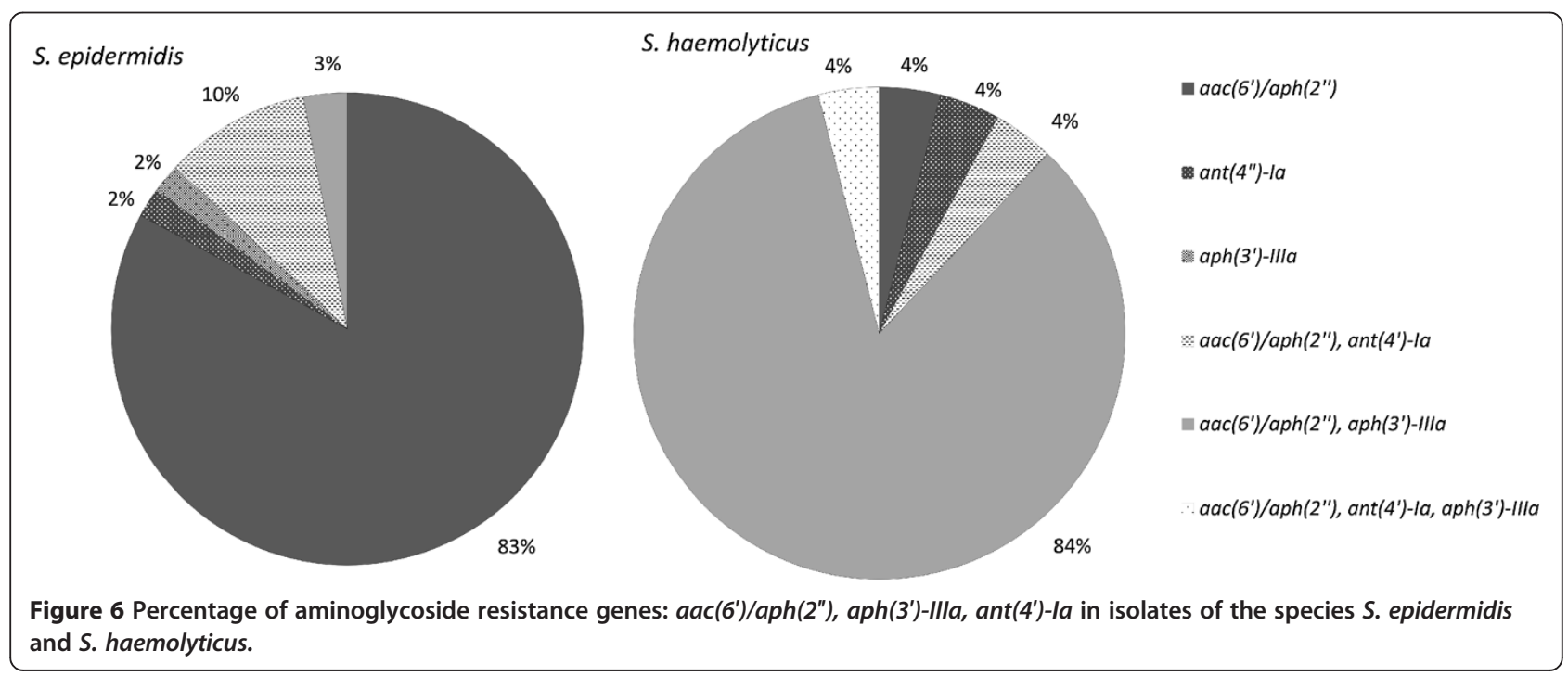


occurred in $90 \%$ of cases. In the case of CNS isolates isolated from neonates researched by Klingenberg et al. $69.4 \%$ of subjects had the $\operatorname{aac}\left(6^{\prime}\right) / \operatorname{aph}\left(2^{\prime \prime}\right)$ gene [21]. Also, among isolates coming from various groups of patients with hospital infections, the main role in coding aminoglycoside resistance had the $\operatorname{aac}\left(6^{\prime}\right) / \operatorname{aph}\left(2^{\prime \prime}\right)$ gene occurring in $70-90 \%$ of CNS isolates [13]. Characteristic of $S$. haemolyticus was the presence, along with the aac $\left(6^{\prime}\right) / a p h\left(2^{\prime \prime}\right)$ gene, of another gene coding aminoglycoside resistance, meaning aph(3')-IIIa (78\%). The comparison of resistance obtained by means of phenotypic methods and genotypic methods enabled observing certain discrepancies. Similarly, Choi et al. observed that only in ca. $50 \%$ of CNS isolates there existed a correlation between the phenotype of amikacin resistance and the genotype [13]. According to recommendations of EUCAST (2012) [10], the isolates demonstrating gentamicin resistance are to be treated as having a general aminoglycoside resistance with the exception of streptomycin, as this one is most probably coded by the aac (6')/aph( $\left.2^{\prime \prime}\right)$ gene the product of which modifies antibiotics such as gentamicin, kanamycin, tobramycin and amikacin [22]. The phenotype of gentamicin resistance, despite the missing $\operatorname{aac}\left(6^{\prime}\right) / \operatorname{aph}\left(2^{\prime \prime}\right)$ gene, may be caused by the presence of other genes coding aminoglycoside resistance which were not determined in the method used. The observed lack of aminoglycoside resistance phenotype in 3 isolates of $S$. epidermidis having the aac $\left(6^{\prime}\right) / a p h$ $(2 ")$ gene probably signifies the loss of functionality of that gene.

The determination of glycopeptide resistance constitutes a significant part of the characteristics of the CNS isolates as these antibiotics are most frequently administered in the empirical treatment of MRCNS infections in VLBW neonates. In the pool of the studied CNS isolates, all of them were susceptible to vancomycin, which is concurrent with observations made by other researchers dealing with CNS isolated from neonatal infections [5,6,17]. Nevertheless, the MIC value for individual isolates achieved the point of $4 \mathrm{mg} / \mathrm{L}$ which is the cut-off point for resistant isolates [10]. The fact of obtaining vancomycin resistance by coagulase-negative staphylococci is confirmed by cases of vancomycin resistance among CNS isolates isolated from infections in various groups of patients, which were recorded by several different research groups [23]. In the case of teicoplanin in the pool of isolates researched, resistance was proven for $13 \%$ of $S$. epidermidis and $3 \%$ of S. haemolyticus, which constitutes a conformation of increasing glycopeptide antibiotic resistance. Similar results were obtained by Trueba et al. where $30.4 \%$ of isolates of S. epidermidis and $35.7 \%$ of S. haemolyticus turned out to be teicoplanin-resistant [24] and Kristyof et al. where $32 \%$ of S. haemolyticus demonstrated resistance [25].

\section{Conclusions}

The multi-drug resistance profiles obtained for isolates of coagulase-negative staphylococci isolated from infections of VLBW neonates hospitalized in NICUs indicate that there is a need to constantly monitor the resistance of these strains. At present, the drugs of choice are vancomycin and teicoplanin with the reservation that a quick selection of teicoplanin-resistant isolates of CNS is possible.

\section{Competing interests}

The authors declare that they have no competing interests.

\section{Authors' contributions}

MBW designed the study, analyzed and interpreted the data, financially supported the study and wrote the manuscript; MBK and EG collected the data about VLBW neonates; MS collected the CNS isolates; MG and ML performed the molecular studies; JWM and PBH designed the Polish Neonatology Surveillance Network (PNSN); MB prepared the literature. All authors read and approved the final manuscript.

\section{Acknowledgements}

The study was approved by Jagiellonian University Bioethical Committee decision no. KBET/94/B/2009. This study was supported by a grant from the National Science Centre no. N N401 615340.

\section{Author details}

${ }^{1}$ Department of Bacteriology, Microbial Ecology and Parasitology, Chair of Microbiology, Jagiellonian University Medical College, Czysta Street 18, 31-121, Krakow, Poland. ${ }^{2}$ Neonatal and Intensive Care Department Medical University of Warsaw, Warsaw, Poland. ${ }^{3}$ Polish Mother's Memorial Hospital, Lodz, Poland. ${ }^{4}$ Duchess Anna Mazowiecka Teaching Hospital, Warsaw, Poland. ${ }^{5}$ Department of Epidemiology of Infection, Chair of Microbiology, Jagiellonian University Medical College, Krakow, Poland.

Received: 17 October 2013 Accepted: 15 December 2013 Published: 20 December 2013

\section{References}

1. Otto M: Staphylococcus epidermidis - the 'accidental' pathogen. Nat Rev Microbiol 2009, 7:555-567.

2. Gheibi S, Fakoor Z, Karamyyar M, Khashabi J, Ilkhanizadeh B, Farzin Asghari-Sana F, Mahmoodzadeh H, Majlesi A: Coagulase Negative Staphylococcus; the Most Common Cause of Neonatal Septicemia in Urmia, Iran. Iran J Pediatr 2008, 18:237-243.

3. Hira V, Sluijter M, Estevão S, Horst-Kreft D, Ott A, De Groot R, Hermans PW, Kornelisse RF: Clinical and molecular epidemiologic characteristics of coagulase-negative staphylococcal bloodstream infections in intensive care neonates. Pediatr Infect Dis J 2007, 26:607-612.

4. Dimitriou G, Fouzas S, Giormezis N, Giannakopoulos I, Tzifas S, Foka A, Anastassiou DE, Spiliopoulou I, Mantagos S: Clinical and microbiological profile of persistent coagulase-negative staphylococcal bacteraemia in neonates. Clin Microbiol Infect 2011, 17:1684-1690.

5. Villari P, Sarnataro C, lacuzio L: Molecular Epidemiology of Staphylococcus epidermidis in a Neonatal Intensive Care Unit over a Three-Year Period. J Clin Microbiol 2000, 38:1740-1746.

6. Abd El Hafez M, Khalaf NG, El Ahmady M, Abd El Aziz A, Hashim Ael G: An outbreak of methicillin resistant Staphylococcus epidermidis among neonates in a hospital in Saudi Arabia. J Infect Dev Ctries 2011, 5:692-699.

7. Qu Y, Daley A, Istivan T, Garland S, Deighton M: Antibiotic susceptibility of coagulase -negative staphylococci isolated from very low birth weight babies: comprehensive comparisons of bacteria at different stages of biofilm formation. Ann Clin Microbiol Antimicrob 2010, 9:16.

8. Gastmeier P, Geffers C, Schwab F, Fitzner J, Oblader M, Rüden H: Development of a surveillance system for nosocomial infections: the component for neonatal intensive care in Germany. J Hosp Infect 2004, 57:126-131

9. Wojkowska-Mach J, Borszewska-Kornacka M, Domanska J, Gadzinowski J, Gulczynska E, Helwich E, Kordek A, Pawlik D, Szczapa J, Klamka J, Heczko PB: 
Early-onset infections of very-low-birth-weight infants in Polish neonatal intensive care units. Pediatr Infect Dis J 2012, 31:691-695.

10. EUCAST - European Committee on Antimicrobial Susceptibility Testing: Version 2.0, valid from 2012-01-01; 2012. http://www.eucast.org/fileadmin/src/media/PDFs/ EUCAST_files/Disk_test_documents/EUCAST_breakpoints_v_2.0_120101.pdf.

11. Pereira EM, Schuenck RP, Malvar KL, lorio NL, Matos PD, Olendzki AN, Oelemann WM, Dos Santos KR: Staphylococcus aureus, Staphylococcus epidermidis and Staphylococcus haemolyticus: methicillin-resistant isolates are detected directly in blood cultures by multiplex PCR. Microbiol Res 2010, 165:243-249.

12. Zmantar T, Chaieb K, Ben Abdallah F, Ben Kahla-Nakbi A, Ben Hassen A, Mahdouani K, Bakhrouf A: Multiplex PCR detection of the antibiotic resistance genes in Staphylococcus aureus strains isolated from auricular infections. Folia Microbiol 2008, 53:35-362.

13. Choi SM, Kim SH, Kim HJ, Lee DG, Choi JH, Yoo JH, Kang JH, Shin WS, Kang MW: Multiplex PCR for the detection of genes encoding aminoglycoside modifying enzymes and methicillin resistance among Staphylococcus species. J Korean Med Sci 2003, 18:631-636.

14. Stoll BJ, Hansen N, Fanaroff AA, Wright LL, Carlo WA, Ehrenkranz RA, Lemons JA, Donovan EF, Stark AR, Tyson JE, Oh W, Bauer CR, Korones SB, Shankaran S, Laptook AR, Stevenson DK, Papile LA, Poole WK: Late-onset sepsis in very low birth weight neonates: the experience of the NICHD Neonatal Research Network. Pediatrics 2002, 110:285-291.

15. Crossley K, Jefferson K, Archer G, Fowler V: Saphylococci In Human Disease. Oxford: Wiley- Blackwell; 2009.

16. Bialkowska-Hobrzanska H, Jaskot D, Hammerberg J: Molecular characterization of the coagulase-negative staphylococcal surface flora of premature neonates. J Gen Microbiol 1993, 139:2939-2944.

17. van den Hoogen A, Gerards L, Verboon-Maciolek M, Fleer A, Krediet T: Long-term trends in the epidemiology of neonatal sepsis and antibiotic susceptibility of causative agents. Neonatol 2010, 97:22-28.

18. Gherardi G, De Florio L, Lorino G, Fico L, Dicuonzo G: Macrolide resistance genotypes and phenotypes among erythromycin-resistant clinical isolates of Staphylococcus aureus and coagulase-negative staphylococci, Italy. FEMS Immunol Med Microbiol 2009, 55:62-67.

19. Gatermann SG, Koschinski T, Friedrich S: Distribution and expression of macrolide resistance genes in coagulase-negative staphylococci. Clin Microbiol Infect 2007, 13:777-781.

20. Bouchami O, Achour W, Mekni MA, Rolo J, Ben HA: Antibiotic resistance and molecular characterization of clinical isolates of methicillin-resistan coagulase-negative staphylococci isolated from bacteremic patients in oncohematology. Folia Microbiol 2011, 56:122-130.

21. Klingenberg C, Sundsfjord A, Rønnestad A, Mikalsen J, Gaustad P, Flaegstad T: Phenotypic and genotypic aminoglycoside resistance in blood culture isolates of coagulase-negative staphylococci from a single neonatal intensive care unit, 1989-2000. J Antimicrob Chemother 2004, 54:889-896.

22. Liakopoulos A, Foka A, Vourli S, Zerva L, Tsiapara F, Protonotariou E, Dailiana Z, Economou M, Papoutsidou E, Koutsia-Carouzou C, Anastassiou ED, Diza E, Zintzaras E, Spiliopoulou I, Petinaki E: Aminoglycoside-resistant staphylococci in Greece: prevalence and resistance mechanisms. Eur J Clin Microbiol Infect Dis 2011, 30:701-705.

23. Juárez-Verdayes MA, Reyes-López MA, Cancino-Díaz ME, Muñoz-Salas S, Rodríguez-Martínez S, de la Serna FJ, Hernández-Rodríguez CH, Cancino-Díaz JC: Isolation, vancomycin resistance and biofilm production of Staphylococcus epidermidis from patients with conjunctivitis, corneal ulcers, and endophthalmitis. Rev Latinoam Microbiol 2006, 48:238-246.

24. Trueba F, Garrabe E, Hadef R, Fabre R, Didier CJ, Tsvetkova K, Chesneau O: High prevalence of teicoplanin resistance among Staphylococcus epidermidis strains in a 5-year retrospective study. J Clin Microbiol 2006, 44:1922-1923.

25. Kristóf K, Kocsis E, Szabó D, Kardos S, Cser V, Nagy K, Hermann P, Rozgonyi F: Significance of methicillin-teicoplanin resistant Staphylococcus haemolyticus in bloodstream infections in patients of the Semmelweis University hospitals in Hungary. Eur J Clin Microbiol Infect Dis 2011, 30:691-699.

\section{doi:10.1186/1476-0711-12-41}

Cite this article as: Brzychczy-Wloch et al:: Prevalence of antibiotic resistance in multi-drug resistant coagulase-negative staphylococci isolated from invasive infection in very low birth weight neonates in two Polish NICUs. Annals of Clinical Microbiology and Antimicrobials 2013 12:41.

\section{Submit your next manuscript to BioMed Central and take full advantage of:}

- Convenient online submission

- Thorough peer review

- No space constraints or color figure charges

- Immediate publication on acceptance

- Inclusion in PubMed, CAS, Scopus and Google Scholar

- Research which is freely available for redistribution 